infrastructure needs. In 2006, the ESFRI released its first roadmap: a list of 35 already-proposed infrastructure projects that the forum deemed to be of pan-European interest. The projects on that list ranged from the large - $\mathrm{a} € 1$-billion, 5-megawatt neutron spectroscopy facility known as the European Spallation Source - to the small: $\mathrm{a} € 12$-million digital infrastructure for the arts and humanities.

Then on 9 December, at its meeting in Versailles, France, the ESFRI released an updated roadmap that lists 44 projects, including all but one of the original 35. The construction cost for all 44 initiatives over the next 12 years would be about $€ 18$ billion. But the EU's Seventh Framework research programme allocates just $€ 1.7$ billion to such costs; the shortfall will need to come from elsewhere.

The creation of the ESFRI is an important first step, but it is not nearly enough: the forum neither funds the projects nor sets explicit priorities among them. Some research communities have started to set their own priorities - a notable recent example being the astronomers (see Nature 456, 427; 2008) - and other communities should certainly follow their lead. But no one is setting Europe's infrastructure priorities across science as a whole.

Such priority-setting is only going to become more urgent as budgets tighten during the economic downturn. So the EU's next step should be to set up an independent European authority that has the power to evaluate infrastructure projects on the basis of their scientific promise, to prioritize them and, ultimately, to fund them. The European Research Council (ERC), which funds basic research on the sole basis of scientific excellence, could serve as a model.

Indeed, such a 'European Research Infrastructure Council' might even serve to stimulate additional funding - just as the ERC process has encouraged member states to fund top-notch projects that have been rejected by the ERC on the basis of its limited budget.

Granted, the creation of such a body would require a transfer of national responsibility and substantial research money - things that are hard to make palatable to national governments. And the new organization would have to deal with the headaches that follow from Europe's wildly varying finance, licensing, tax and social-security systems. Nonetheless, it could pool money, competence and negotiating power, and vastly improve the painstakingly slow process of supplying scientists in Europe with the tools they need to produce the kind of collaborative research they are expected to deliver.

Scientists prove every day that true collaboration can be every bit as successful in Europe it is elsewhere. It is the responsibility of EU policy-makers to make sure that this doesn't change.

\section{Eyes west}

\section{Could the United States topple Europe as the driver of international climate-change regulations?}

\footnotetext{
T
} he recently concluded United Nations conference on climate change, in Poznań, Poland (see page 846), marked the last phase of eight years of foot-dragging by US negotiators. For one last time, the designated US representatives at international climate talks came from the administration of President George W. Bush, who rejected the Kyoto Protocol almost immediately after taking office and whose team has stalled any meaningful progress since.

But by this time next year, when the world's negotiators convene in Copenhagen to try to hammer out a deal to succeed the Kyoto accord, the lame ducks will be gone. In their place will be representatives of a new US president, Barack Obama, who has promised to make control of greenhouse-gas emissions a central focus of his administration.

How much progress Obama can make in his first 11 months remains to be seen, and it is far from clear that the world will be able to fashion a workable consensus in Copenhagen. But a consensus now seems much more likely than it was.

As if to dramatize how difficult the task will be, European Union (EU) representatives crashed and burned last week as they attempted to lay out the next phase of Europe's otherwise groundbreaking emissions trading scheme (see page 847). Caving to political pressure from Italy and Poland, among others, French president and outgoing EU chief Nicolas Sarkozy crafted a compromise that satisfies many — in the fossil-fuel industry, that is. Rather than holding heavy industries accountable for their emissions, the new deal gives the heaviest polluters significant leeway. The very industries that account for some of the highest levels of emissions, such as steel and cement, can now apply for exemptions that could grant them free emissions permits even after 2020. Everyone else will have to start paying in 2013.

EU leaders praised the deal, but the concessions it contains are likely to harm the trading system irrevocably, allowing industry to further delay the radical changes needed to clean up its business.

Climate leadership may pass instead to the United States, which will need to set tough emissions limits - and stick to them - if it wants to do better than Europe. If Obama is as serious as he claims to be about establishing a cap-and-trade regime, his administration will need to carefully consider the lessons of the European experience. For starters, a US system should avoid giving away emission permits so freely, and consider setting a minimum price for them.

A promising development on this front is Obama's appointment of Steven Chu, a Nobel prizewinning physicist and energy-technology advocate, as secretary of energy (see page 849). The energy department spent US\$1.4 billion on research and development for renewable, fossil and nuclear energies in 2008 - less than a quarter of what it was 30 years before, when adjusted for inflation. Chu, who made renewable energy the raison d'etre of California's Lawrence Berkeley National Laboratory, which he has led since 2004, should reverse that trend. Chu not only 'gets' climate change, he gets its urgency. Private investment is making incremental advances in the short-term cost-effectiveness of renewable energy. But technology-driven, order-of-magnitude leaps are essential in the medium term: time for the long term has run out.

It was in 1997 - the year the Kyoto Protocol was adopted - that Chu won his Nobel prize for cooling atoms to a near standstill with laser light. He did the work at the now-moribund Bell Labs in New Jersey a place $\mathrm{Chu}$ fondly remembers for favouring boldness. "Some failure was expected," Chu said at a recent seminar, "but there was an emphasis on recognizing failure quickly, and moving on to other opportunities." That is a credo worth adopting - both in the creation of carbon-free energies, and in the creation of carbon-emission markets. 